\title{
Application of Sludge Bed Filter for Advanced Treatment of SS and Nitrate-N Removal
}

\author{
Kyung-Jin $\mathrm{CHO}^{1)}$ and Tomohide WATANABE ${ }^{2)}$ \\ ${ }^{1)}$ R\&DB Center 301, Kyungil University, 33, Buho-ri, Hayang-eup, Gyeongsan-si, \\ Gyeongsangbuk-do, KOREA \\ 2) Department of Civil Engineering, Gunma University, 1-5-1 Tenjin, Kiryu, Gunma, 376-8515, \\ JAPAN \\ (E-mail: kjcho357@gmail.com)
}

\begin{abstract}
The objective of this study is to identify the characteristics of SS and nitrate removal using hybrid sludge bed filter and combined with electrode system for advanced treatment of secondary clarifier effluents. The following results were obtained. The hybrid filter could remove SS and nitrate simultaneously. Larger particles than about $5 \mu \mathrm{m}$ in diameter were removed completely at filtration rate $15 \mathrm{~m} \cdot \mathrm{d}^{-1}$ and sludge bed thickness $20 \mathrm{~cm}$. The head loss of the filter was less than $0.34 \mathrm{~m}$ of water at the highest value. The denitrification rate by the bio-electrochemical process was estimated to be around $0.036 \mathrm{~kg}-\mathrm{N} \cdot \mathrm{kg}-\mathrm{SS}^{-1} \cdot \mathrm{day}^{-1}$ at the applied electric current density, $0.76 \mathrm{~mA} \cdot \mathrm{cm}^{-2}$ and the endogenous denitrification rate in the subsided sludge bed was $0.0052 \mathrm{~kg}-\mathrm{N} \cdot \mathrm{kg}-\mathrm{SS}^{-1} \cdot \mathrm{day}^{-1}$. The nitrate removal rate was enriched by the bio-electrochemical reaction. The hybrid filter may be substituted for conventional granular bed and bio-filters from not only the SS removal point of view but also nitrate removal point of view.
\end{abstract}

Key words

Hybrid Sludge Bed Filter, Advanced Treatment, Particle size, SS removal, Nitrate-N Removal

\section{INTRODUCTION}

Advanced wastewater treatment is one of the most important requirement for wastewater reuse and water environment protection. One of the feasible advanced treatment schemes includes filtration of secondary clarifier effluent. As the major subject for advanced treatment is the removal of remained nitrate and suspended solids in the effluent of which concentrations are relatively low, they are treated with separate filtration processes, in which granular bed and bio-filters are widely used. Granular bed filters made of fine sand particles in the range of several hundreds $\mu \mathrm{m}$ to $2 \mathrm{~mm}$ in diameter are operated under the conditions of slow and rapid filtration rates, which are about $5 \mathrm{~m} \cdot \mathrm{d}^{-1}$ and $100 \sim 400 \mathrm{~m} \cdot \mathrm{d}^{-1}$, respectively(Adin and Elimelech, 1989; Baumann and Haung, 1974). In the former, large particles are removed on the surface of the bed, while small particles of several $\mu \mathrm{m}$ in diameter are adhered and removed in the deep bed. The removal efficiency of small particles is high and the head loss of the bed is very large even in such slow filtration rate. In the latter, large diameter particles are adhered and removed in the deep bed and the head loss of the bed is high. The washing operation of the bed is essentially required to remove and reduce clogged particles in the bed for continuous operations. The removal efficiency of small particles is poor and small particles less than about $15 \mu \mathrm{m}$ in diameter are passed through the bed. And also the removal efficiency of dissolved matter such as BOD and nitrate is poor for both slow and rapid filtrations. This is the reason why bio-filters are used to polish the effluent.

If a hybrid filter combined with both bio-filters and granular bed filters could be applied, nitrate and suspended solids(SS) may be removed simultaneously and the process may be 
simplified to one unit.

When activated sludge flocks subside and accumulate on a solid plate, the accumulated flocks are squeezed up against each other and made into a subsided bed. As the subsided bed is composed of flocks, it is porous and supple (Lin and Miller, 2000; Wakeman, 1999). The bed structure is close to that of biofilms (Kuroda, 1988; Zewandwski, 2000). These characteristics are very different from that of granular beds. When it is used as filter media, the filter may show the characteristics combined of both granular bed and bio- filters, provided electron donor and electron acceptor are fed effectively. As the bio-electrochemical method is used for electron donor and electron acceptor supply is very effective (Kuroda et al, 1996, 1997; Sakakibara and Kuroda, 1993; Sakakibara et al, 1994; Szilvia Szekeres et al, 2001; Tanaka and Kuroda, 2000; Watanabe et al, 2001, 2002). A hybrid filter consisted of the subsided sludge bed and electrode system has been developed and the performance of the hybrid filter has been investigated.

The objective of the studies reported in this paper was to identify the characteristics of SS and nitrate removal using hybrid sludge bed filter and combined with electrode system for advanced treatment of secondary clarifier effluents.

\section{MATERIALS AND METHODS}

\section{Apparatus}

Fig. 1 shows the experimental apparatus. A subsided sludge bed was formed by settling and compressing suspended activated sludge naturally on a thin porous sheet. Two hybrid filters were constructed, which are Type1 (SB filter) where the electrode system was inserted to the subsided sludge bed and Type 2 (SBE filter) separated the electrode system from the subsided sludge bed. In the SBE filter, the subsided sludge bed followed the bed packed with inoculated porous carriers accompanying the electrode system.

The subsided sludge bed works as a deep bed filter to remove SS and also works as a bio-filter to removes nitrate and BOD, provided electron donor and electron acceptor are supplied effectively. In the bio-electrochemical method, electron donor and electron acceptor such as $\mathrm{H}_{2}$ and $\mathrm{O}_{2}$ are produced by electrolysis of water on electrode surfaces and the production rates are effectively controlled by current. 


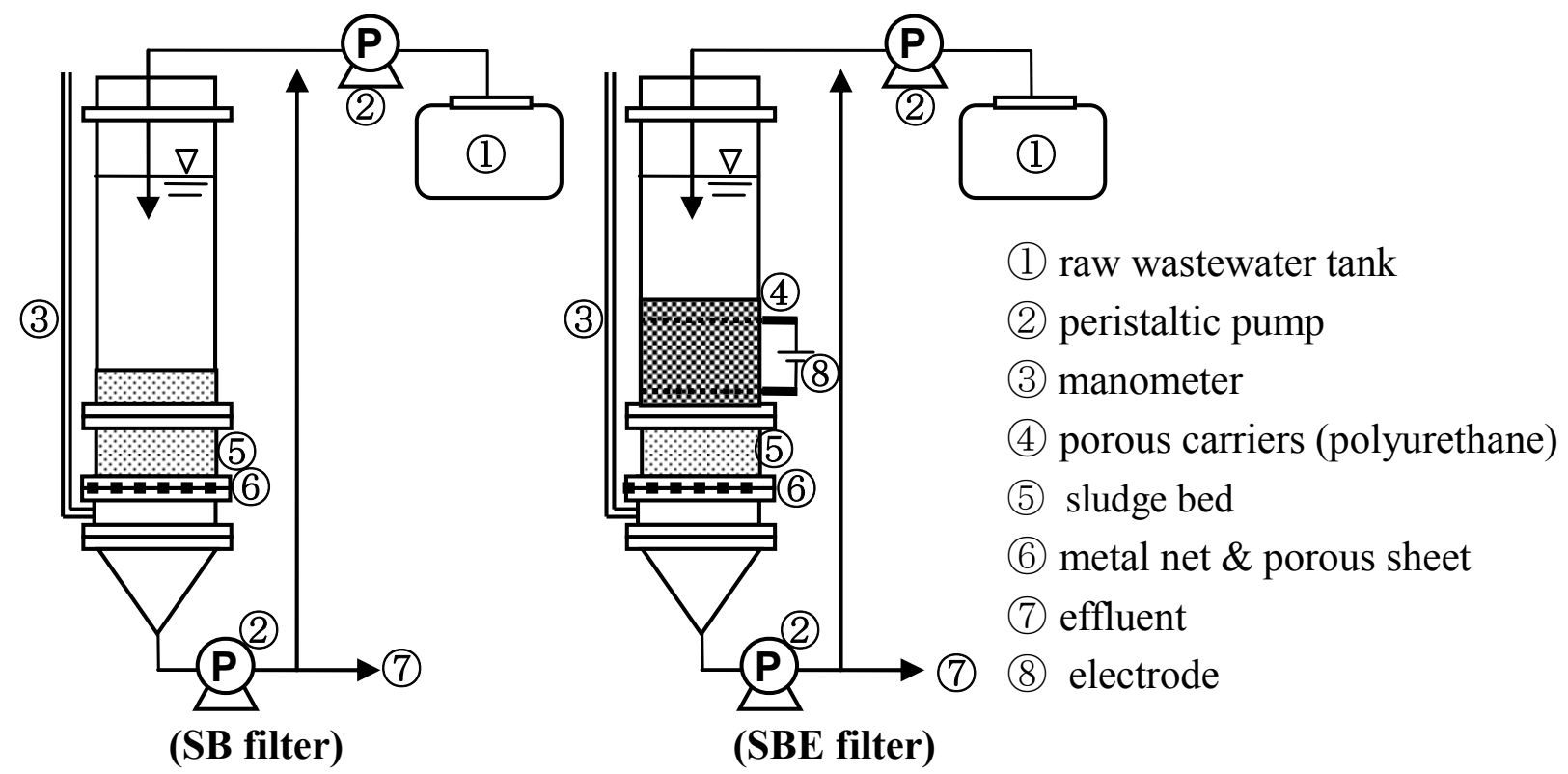

Fig.1 Experimental apparatus 


\section{SS removal and particle size distribution by using the SB filter}

The subsided sludge bed used was about $2 \sim 5 \mathrm{~cm}$ thick. The diameters of the bed and the perforated plate-electrode inserted were $5 \mathrm{~cm}$. The filtration rates were varied in the range of 5 $\mathrm{m} \cdot \mathrm{d}^{-1}$ to $40 \mathrm{~m} \cdot \mathrm{d}^{-1}$. Synthetic wastewater of which SS concentration is $8 \sim 10 \mathrm{mg} \cdot \mathrm{l}^{-1}$ was used as samples. Secondary clarifier effluent and synthetic wastewater to which sodium nitrate and activated sludge were added in secondary clarifier effluent were used as samples.

The experiments were carried out by feeding the Cryptracer No.1(specific gravity; 1.19, quality ; polymethylmethacrylate, particle size ; $5 \mu \mathrm{m} \pm 0.5$, Blue in the UV excitation, Japan Water Research Center) $\times 10^{8}$ number $\cdot 1^{-1}$ for Cryptosporidium parvum $(5 \mu \mathrm{m})$ at thickness of the subsided sludge bed $0.02 \mathrm{~m}$ and the filtration rates $5 \mathrm{~m} \cdot \mathrm{d}^{-1}$.

\section{SS removal and denitrification by using the SBE filter}

The external surface area of one cathode was $16.4 \mathrm{~cm}^{2}$ and applied electric current 12.5mA. The distance between the anode and the cathode was about $5 \mathrm{~cm}$. Synthetic wastewater used as samples of which SS and $\mathrm{NO}_{3}-\mathrm{N}$ concentrations are 10 and $30 \mathrm{mg} \cdot \mathrm{l}^{-1}$, respectively.

\section{Analytical methods}

Particle diameter distributions were measured with a laser diffraction particle size analyzer (Shimadzu Laser Diffraction Particle-size Analyzer SALD-300V). For the measurement of dissolved constituents were filtered through membrane filters with $200 \mathrm{~nm}$ of nominal pore size and were subjected to analyses. Nitrate and nitrite were analyzed by an ion chromatography (Yokogawa Analytical Systems, IC-7000).

\section{RESULTS AND DISCUSSION}

\section{SS removal}

Typical experimental results by using the SB filter are shown in Fig.2. The thickness of the subsided bed was $0.03 \mathrm{~m}$ and the filtration rates were varied from $20 \mathrm{~m} \cdot \mathrm{d}^{-1}$ to $40 \mathrm{~m} \cdot \mathrm{d}^{-1}$. As shown in Fig. 2 the SS concentration of filtrate was about $2 \mathrm{mg} \cdot 1^{-1}$ even at the filtration rate of $40 \mathrm{~m} \cdot \mathrm{d}^{-1}$. The head loss of the bed was increased in increasing the filtration rate and time. The largest head loss was about $0.65 \mathrm{~m}$ of water. This value is smaller than that of conventional slow and rapid sand filters. The rate of SS removal was 80 to $90 \%$.

\section{Particle size distribution}

Variations of Cryptracer concentrations in influent and effluent by using the SB filter was shown in Fig.3 The sludge bed thickness was $2 \mathrm{~cm}$ and filtration rate was $5 \mathrm{~m} \cdot \mathrm{d}^{-1}$. The concentrations in the effluent were in the range $2.0 \sim 3.5 \times 10^{7}$ number $\cdot 1^{-1}$ and the rate of Cryptracer removal was about $70 \%$. This indicates that larger particles than about $5 \mu \mathrm{m}$ in diameter were removed effectively by using the sludge bed filter. 


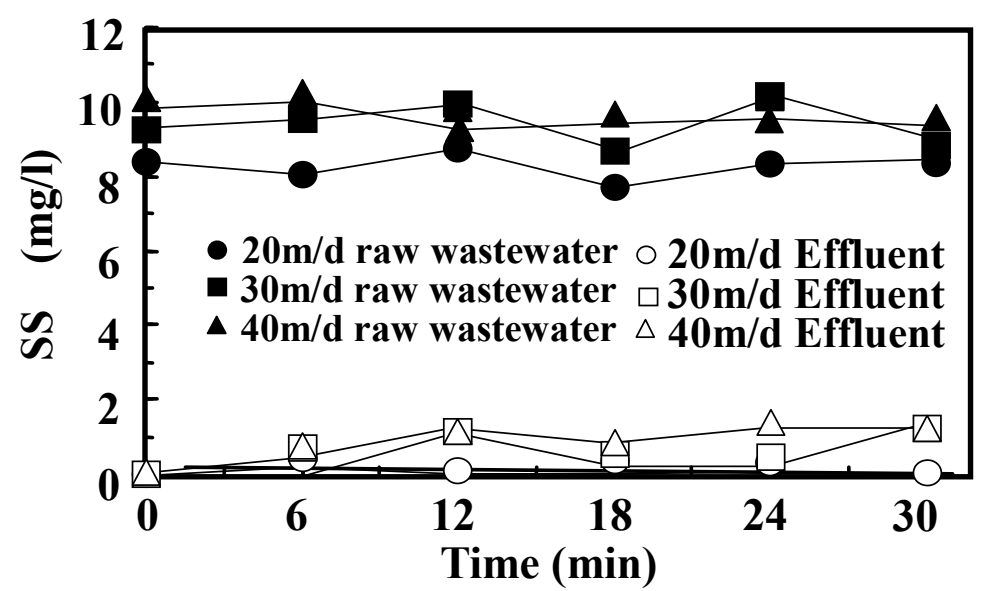

Fig. 2 Effects of filtration rates for SS removal (sludge bed thickness ; $3 \mathrm{~cm}$ )

Typical experimental results by using the SB filter are shown in Fig.4. The thickness of the subsided bed was $3 \mathrm{~cm}$ and the filtration rate was $10.5 \mathrm{~m} \cdot \mathrm{d}^{-1}$. There were three peaks of particle diameters for the sample wastewaters, which were about 2, 30 and $100 \mu \mathrm{m}$ respectively. The largest particle diameter was about $300 \mu \mathrm{m}$. On the other hand, there were one or two peaks for the filtrates, of which peak diameter was varied with duration of operating time. Larger particles than about $10 \mu \mathrm{m}$ in diameter were removed completely. The peak of particle diameter moved to smaller particles less than about $5 \mu \mathrm{m}$ in diameter after the duration of 300 minutes.

The head loss of the bed was increased in increasing the duration of operating time and the head loss after the duration of 300 minutes was about $0.65 \mathrm{~m}$ of water. This suggests that the subsided sludge bed was compressed with the duration of operating time. However the value of head loss was smaller than that of conventional slow and rapid sand filtrations. This small head loss suggests that the subsided sludge bed is supple.

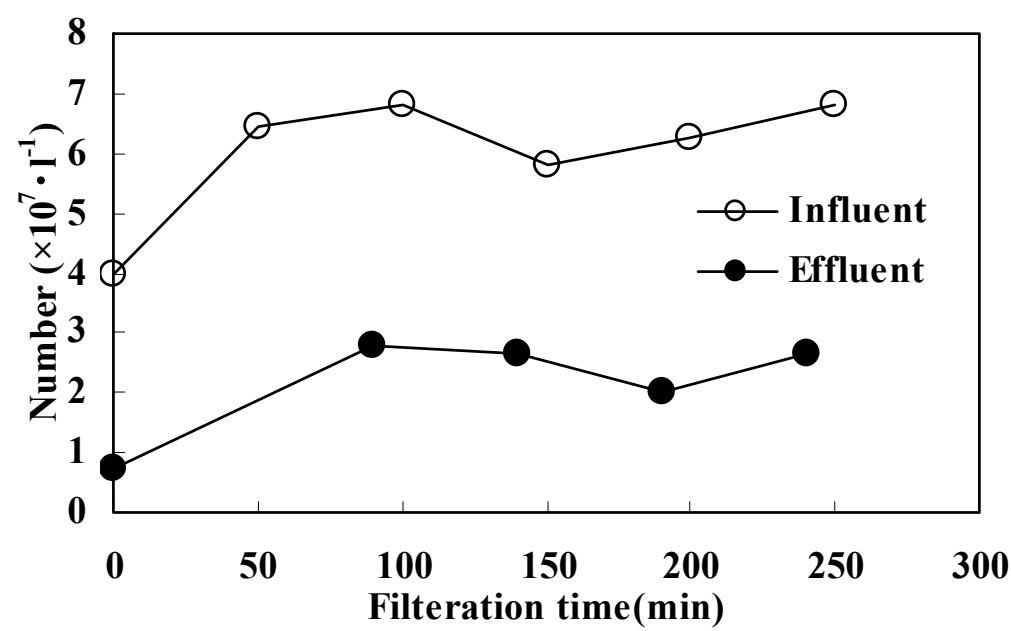

Fig. 3 Variations of Cryptracer concentrations in influent and effluent (sludge bed thickness $; 2 \mathrm{~cm}$, filtration rate $; 5 \mathrm{~m} \cdot \mathrm{d}^{-1}$ ) 

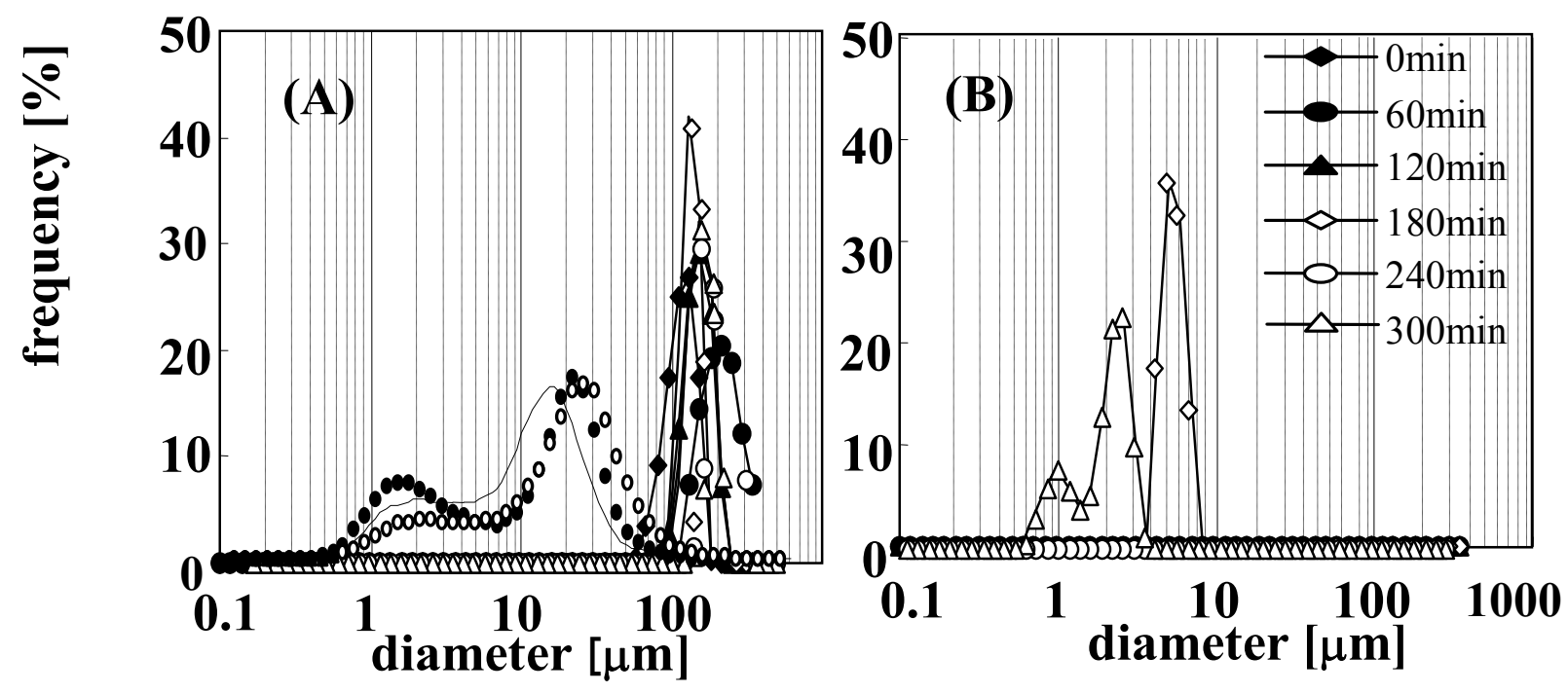

Fig. 4 Particle size distribution of sample wastewater(A), filtrate(B) $\left(\right.$ filtration rate $\left.=10.5 \mathrm{~m} \cdot \mathrm{d}^{-1}\right)$

\section{Denitrification}

Fig.5 shows the SS and Nitrate-N concentrations in the effluent at filtration rate $5.3 \mathrm{~m} \cdot \mathrm{d}^{-1}$ by SBE filter. The endogenous denitrification proceeded in the sludge bed but the rate was low. The denitrification rate by a bio-electrochemical process in the hybrid filter was estimated to be around $0.036 \mathrm{~kg}-\mathrm{N} \cdot \mathrm{kg}-\mathrm{SS}^{-1} \cdot \mathrm{d}^{-1}$ at the applied electric current density, $0.76 \mathrm{~mA} \cdot \mathrm{cm}^{-2}$. The endogenous denitrification rate in the subsided sludge bed was $0.0052 \mathrm{~kg}-\mathrm{N} \cdot \mathrm{kg}-\mathrm{SS}^{-1} \cdot \mathrm{d}^{-1}$. The nitrate removal rate was enriched by the bio-electrochemical reaction. Electron donor and electron acceptor such as $\mathrm{H}_{2}$ and $\mathrm{O}_{2}$ were supplied and controlled by electric current, which were produced on the electrode surfaces through electrolysis of water.

These results suggested that the hybrid filter may be substituted for conventional granular bed and bio-filters from not only the SS removal point of view but also nitrate removal point of view.

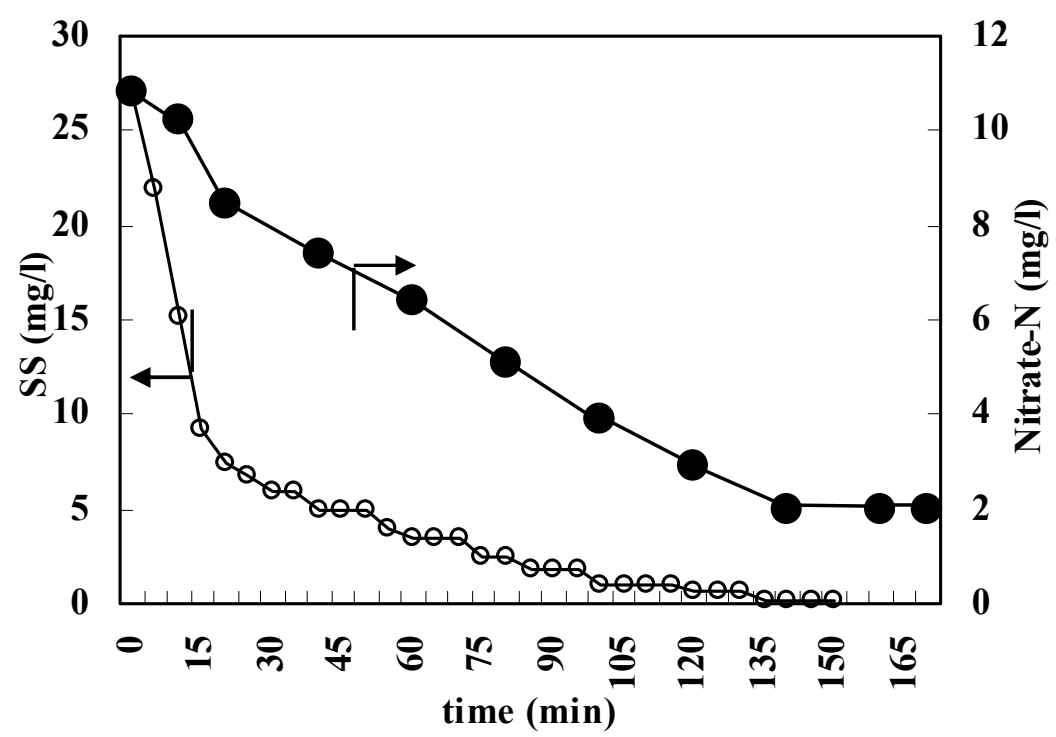

Fig. 5 Variations of SS and Nitrate-N concentrations by SBE filter (filtration rate $; 5.3 \mathrm{~m} \cdot \mathrm{d}^{-1}$ ) 


\section{CONCLUSIONS}

The hybrid filter combined with a subsided bed and electrode system has been developed and the hybrid filter applied for an advanced treatment of secondary clarifier effluents to remove SS and nitrate. The following results were obtained.

The hybrid filter could remove SS and nitrate simultaneously. Larger particles than about $10 \mu \mathrm{m}$ in diameter were removed completely. However, the value of head loss was 0.65 $\mathrm{m}$ at the highest value smaller than that of conventional slow and rapid sand filtrations.

The denitrification rate by the bio-electrochemical process was estimated to be around $0.036 \mathrm{~kg}-\mathrm{N} \cdot \mathrm{kg}-\mathrm{SS}^{-1} \cdot \mathrm{d}^{-1}$ at the applied electric current density, $0.76 \mathrm{~mA} \cdot \mathrm{cm}^{-2}$ and the endogenous denitrification rate in the subsided sludge bed was $0.0052 \mathrm{~kg}-\mathrm{N} \cdot \mathrm{kg}-\mathrm{SS}^{-1} \cdot \mathrm{d}^{-1}$. The nitrate removal rate was enriched by the bio-electrochemical reaction. Electron donor and electron acceptor such as $\mathrm{H}_{2}$ and $\mathrm{O}_{2}$ were supplied and controlled by electric current, which were produced on the electrode surfaces through electrolysis of water.

The hybrid filter may be substituted for conventional granular bed and bio-filters from not only the SS removal point of view but also nitrate and BOD removal point of view.

\section{Acknowledgements}

The authors thank to K. Kudo, T. Hirota and Dr. Yanqing XU for their contribution to the experimental work.

\section{REFERENCES}

Adin,A. and Elimelech M. (1989) Particle filtration in wastewater irrigation, J.Irrigation and Drainage Eng. ASCE, 115(3), 293-304.

Baumann,E.R.and Haung J.Y.C. (1974) Granular filter for tertiary wastewater treatment, WPCF, 46(8) 1958-1973.

Kuroda M., Yuzawa M., Sakakibara Y. and Okamura Y. (1988) Methanogenic bacteria adhered to solid supports, WaterResearch, 22(5), 653-656.

Kuroda M., Watanabe T. and Umedu Y. (1996) Simultaneous oxidation and reduction treatment of polluted water by bio-electro reactors, Water Science \& Technology, 34, 101-108.

Kuroda M., Sakakibara Y. and Watanabe T. (1997) Development of bio-electro reactor system, International Symposium ENVIRONMENTAL BIOTECHNOLOGY, Part 1, 75-78.

Lin, C.L. and Miller, J.D. (2000) Pore structure and network analysis of filter cake, Chemical Engineering Journal, 221-231.

Sakakibara,Y. and Kuroda M. (1993) Electoric promting and control of denitrification, Biotech. and Bioengg. 42, 535-537.

Sakakibara,Y., Floora J.R.V., Suidan M.S. and Kuroda M. (1994) Modeling of Electrochemically Activated Denitrifying Biofilms, Water Research, 28, 1077-1086.

Szilvia Szekeres, Istvan Kiss, Tuvia Bejerano, T. and Kim. Soares. (2001) Hydrogen-dependent denitrification in a two reactor bio-electrochemical system, Water Research, 35, 715-719.

Tanaka T. and Kuroda, T (2000) Improvement of submerged biofilter process bioelectrochemical method, J. of Environmental Engineering, June 541-548.

Watanabe T. Motoyama H. and Kuroda M. (2001) Denitrification and neutralization treatment by direct feeding oh an acidic wastewater containing copper ion and high strength nitrate to a bio-electro chemical reactor process, Water Research, 35, 4102-4110.

Watanabe T., Hashimoto S. and Kuroda M. (2002) Simultaneous nitrification and denitrification in a single reactor using bio-electrochemical process, Water Science \& Technology, 46, 163-169.

Wakeman, R.J. and E.Tareton E.S. (1999) Filtration, equipment selection modeling and process simulation, Elsevier Advanced Technology.

Zewandwski Z. (2000) Note on biofilm porosity, Water Research, 34(9), 2620-2624. 